\title{
Assets returns volatility and investment horizon: The French case
}

\author{
Frédérique BeC* and Christian Gollier** \\ *THEMA, Université de Cergy-Pontoise et CREST, Malakoff, France. email: bec@ensae.fr \\ **Toulouse School of Economics (LERNA and IDEI), France. email: gollier@cict.fr
}

First version: 4 July 2006

Revised version: Paris, 30 November 2008

\begin{abstract}
This paper explores French assets returns predictability within a VAR setup. Using quarterly data from 1970Q4 to 2006Q4, it turns out that bonds, equities and bills returns are actually predictable. This feature implies that the investment horizon does indeed matter in the asset allocation. The VAR parameters estimates are then used to compute real returns conditional volatility across investment horizons. The results reveal the same kind of horizon effect as the one found in recent empirical studies using quarterly U.S. data. More specifically, the excess annualized standard deviation of French stocks returns with respect to bills and bonds returns decreases as the investment horizon grows. They suggest that long-horizon investors overstate the share of bonds in their portfolio choice when neglecting the horizon effect on risk of asset returns predictability.
\end{abstract}

Keywords: Asset return predictability, Investment horizon, Vector Autoregression. JEL classification: G11.

Acknowledgments: The authors thank Severine Marion and participants at the (EC) ${ }^{2} 2007$ meeting, Faro (Portugal), and at the Finance European Meeting AFFI, Paris, for helpful comments and Carlo Favero for pointing out a mistake in a previous version. They also gratefully acknowledge financial support by the Fédération Française des Sociétés d'Assurance. Frédérique Bec is grateful to the funding by Danish Social Sciences Research Council (2114-04-0001). 


\section{Introduction}

The optimal management of an assets portfolio is dynamic by nature. This basic point was first made by Mossin [1968], Merton [1969] and Samuelson [1969]. However, they concluded that, under the commonly accepted assumptions of that time, the optimal assets allocation is myopic. This means that the investment horizon is irrelevant, or that the optimal dynamic allocation is equivalent to the static one. More generally, Merton [1973] has shown that variation in expected returns over time may induce horizon effects. However, closed-form solutions to Merton's intertemporal model are difficult to find except in the case where the investor has log utility of consumption, i.e., with unit constant relative risk aversion, which is a case of limited interest since it implies that Merton's model reduces to a static one. The lack of closed-form solutions for constant (but not unit) relative risk aversion coefficient explains why so few empirical work was devoted to the horizon effects until very recently. When assets returns are unpredictable, myopia becomes optimal in the more general case of constant relative risk aversion. Increasing the investment period raises both the expected final payoff and its volatility in such a way that these two effects counterbalance each others perfectly under these conditions.

This question of optimal myopia is particularly crucial for financial intermediaries in charge of the management of lifecycle saving programs. Most pension programs now take the form of Defined Contribution plans, which means that most of the financial risk is borne by the individuals contributing to the system. It implies that these financial intermediaries should manage their financial reserves by taking into account the long-term objectives of their customers, which is to accumulate enough wealth for their retirement. The European Union is however considering a new regulation of the solvency of (life) insurance companies in which their capital requirement would be based on the assets and liabilities risks measured on a 12-month basis. In this paper, we raise the question of whether this so-called "Solvency II" myopic rule is efficient from the viewpoint of the policyholders. If we accept the assumption that relative risk aversion is constant, ${ }^{1}$ the answer to this question relies on whether assets returns are predictable or not.

Future assets returns are predictable if they are statistically related to some easily observable variables that are referred to as predictors. Fama and French [1988], Poterba and Summers [1988], Campbell [1996], Campbell, Lo and MacKinlay [1997], Barberis [2000], Cochrane [2001] and many others estimated significant predictability of US stocks returns. In particular, there is mean-reversion in stocks returns, in the sense that shocks in expected stocks returns are negatively correlated with shocks to realized stocks returns. For example, Barberis [2000] used a simple VAR setup for stocks returns with the dividend-price ratio as predictor. He showed that the implied standard deviation of ten-year U.S. stocks returns is 23.7 percent, much smaller than the 45.2 percent value implied by the standard deviation of monthly returns. Using a more sophisticated VAR analysis of bills, bonds and stocks returns with three predic-

\footnotetext{
${ }^{1}$ Gollier and Zeckhauser [2002] examine this question when relative risk aversion is not constant.
} 
tors, Campbell and Viceira [2002] showed that mean-reversion of U.S. stocks returns cuts their standard deviation from $18 \%$ at a one-year horizon to $14 \%$ at a 25 -year horizon.

Because mean-reversion implies that stocks are safer in the long run, the intuition suggests that a long horizon agent should have a larger demand for stocks early in his investment period. Campbell and Viceira [1999] and Barberis [2000] numerically estimated the sensitiveness of the demand for stocks to the investment horizon. The hedging demand for stocks is surprisingly large. For an agent with a relative risk aversion equaling 10 and a ten-year time horizon, the optimal investment in stocks is about $40 \%$ of current wealth without predictability. It goes up to $100 \%$ when mean-reversion is taken into account. This suggests that limiting the risk measurement to 12-month as in the Solvency II reform would inefficiently bias the insurers' assets portfolios towards bonds and bills. Given the large equity premium that has been observed over the past century both in the United States and in Europe (Dimson, Marsh and Staunton [2002]), this regulatory failure could have dramatic effects on the accumulated wealth and welfare of future retirees.

Our contribution to this literature is twofold.

First, one important limitation to applying these ideas to make policy recommendations is that this literature is entirely based on U.S. data. It is a priori not clear whether these findings can be applied to other countries, as long as we don't have a general theory that would explain these serial correlations in assets returns. Our aim in this paper is to see whether the abovementioned findings made on U.S. markets can be extended to France. We use quarterly data from 1970Q4 to 2006Q4 to perform a VAR analysis of real assets returns on French financial markets. We use the following list of predictors to determine the intensity of predictability: past real returns of stocks, bonds and bills, the nominal interest rate, the dividend-price ratio and the spread of interest rates. We closely follow the analysis that was used by Campbell and Viceira [2002], and obtain similar conclusions. Namely, stocks returns are slightly meanreverting, whereas the returns of portfolios of bonds - either rolled or held to maturity exhibit some degree of mean-aversion. The intensity of mean-reversion of French stocks returns is weaker than the one reported by Campbell and Viceira on U.S. data, but we still conlude that the excess risk of stocks on bonds is smaller for long horizons than for short ones.

Second, we depart from existing empirical work by providing $95 \%$ confidence intervals for the various assets risks across horizons. They reveal that the risk associated with equities is actually significantly higher than the one of other assets for short investment horizons, but it becomes statistically undistinguishable from the bonds rolled risk for horizons longer than 5 quarters and from the bonds held to maturity after around six years.

The paper is organized as follows. Section 1 shows how conditional second-order moments of asset returns, i.e. their volatility, can be derived from a VAR setup. Section 2 describes the data used for the VAR model estimation presented in Section 3. In Section 4, French assets conditional volatilities are compared across investment horizons. The robustness of these results is then checked in Section 5 while Section 6 concludes. 


\section{Asset returns predictability and horizon effects from a VAR setup}

A vector autoregressive (VAR) dynamics for U.S. asset returns is considered in e.g. Campbell [1991], Campbell [1996], Barberis [2000] or Campbell and Viceira [2002]. ${ }^{2}$ Beyond asset returns predictability considerations, Campbell and Viceira [2002] analysis emphasizes how well-suited the VAR framework is in order to evaluate investment horizon effects. Following their approach, our empirical study allows an arbitrary set of traded assets and state variables. More specifically, we consider a short-term interest rate together with excess stock returns and excess bond returns. Let $R_{0 t}$ denote the ex post real short rate and $r_{0 t}=\log \left(R_{0 t}\right)$ the $\log$ (or continuously compounded) real return on this asset that is used as a benchmark to compute excess returns on other asset classes. Then, with $r_{e t}$ and $r_{b t}$ the log real stock return and the $\log$ real bond return, let $x_{e t}=r_{e t}-r_{0 t}$ and $x_{b t}=r_{b t}-r_{0 t}$ denote the corresponding log excess returns.

We retain the same VAR(1) system as in Campbell and Viceira [2002] and Campbell et al. $[2003]^{3}$ :

$$
\mathrm{z}_{t}=\Phi_{0}+\Phi_{1} \mathrm{z}_{t-1}+\mathrm{v}_{t}
$$

where

$$
\mathrm{z}_{t}=\left[\begin{array}{l}
r_{0 t} \\
\mathrm{x}_{t} \\
\mathrm{~s}_{t}
\end{array}\right]
$$

is a $m \times 1$ vector with $\mathrm{x}_{t}$, the $n \times 1$ vector of $\log$ excess returns and $\mathrm{s}_{t}$ the $m-n-1 \times 1$ vector of variables which have been identified as returns predictors in existing empirical analysis, such as the nominal short rate, the dividend-price ratio and the yield spread between longterm and short-term bonds. In equation (1), $\Phi_{0}$ is the $m \times 1$ vector of intercepts and $\Phi_{1}$ is the $m \times m$ matrix of slope coefficients. It is assumed that the roots of the characteristic polynomial $\Phi(z)=I_{m}-\Phi_{1} z$ lie strictly outside the unit circle in absolute value, a condition which rules out nonstationary or explosive behavior in $z_{t}$. Finally, $\mathrm{v}_{t}$ is the $m \times 1$ vector of innovations in asset returns and return forecasting variables, which is assumed to be i.i.d. normally distributed:

$$
\mathrm{v}_{t} \sim \mathcal{N}\left(0, \Sigma_{v}\right)
$$

where $\Sigma_{v}$ is the $m \times m$ covariance matrix.

\footnotetext{
${ }^{2}$ Under the assumption that asset returns are well described by such a VAR model, Campbell, Chan and Viceira [2003] show how to obtain approximate solutions to the multiperiod portfolio choice model they propose. In this model, the investor is infinitely-lived with Epstein-Zin utility and there are no borrowing or short-sales constraints on asset allocation.

${ }^{3}$ As emphasized by these authors, the analysis below can be easily extended to more than one lag. However, the number of parameters in a VAR model increases exponentially with the number of lags, which may significantly reduce the estimates precision.
} 
As stressed in Campbell and Viceira [2004], the conditional $k$-period variance-covariance matrix obtains straightforwardly from the VAR model estimates. First, cumulative $k$-period $\log$ returns are obtained by adding one-period log returns over $k$ successive periods. Then, under the assumption that $\Sigma_{v}$ is constant over time ${ }^{4}$, the conditional $k$-period variance is given by:

$$
\begin{aligned}
\operatorname{Var}_{t}\left(\mathrm{z}_{t+1}+\cdots+\mathrm{z}_{t+k}\right)= & \Sigma_{v}+\left(I+\Phi_{1}\right) \Sigma_{v}\left(I+\Phi_{1}\right)^{\prime} \\
& +\left(I+\Phi_{1}+\Phi_{1} \Phi_{1}\right) \Sigma_{v}\left(I+\Phi_{1}+\Phi_{1} \Phi_{1}\right)^{\prime}+\cdots \\
& +\left(I+\Phi_{1}+\cdots+\Phi_{1}^{k-1}\right) \Sigma_{v}\left(I+\Phi_{1}+\cdots+\Phi_{1}^{k-1}\right)^{\prime}
\end{aligned}
$$

In order to extract the conditional moments of real returns from the VAR, we use the following $(n+1) \times m$ selection matrix:

$$
M_{r}=\left[\begin{array}{ccc}
1 & \mathbf{0}_{1 \times n} & \mathbf{0}_{1 \times(m-n-1)} \\
\imath_{n \times 1} & \mathbf{I}_{n \times n} & \mathbf{0}_{n \times(m-n-1)}
\end{array}\right]
$$

in (4). Then, dividing both sides by the horizon in order to annualize, we get:

$$
\frac{1}{k} \operatorname{Var}_{t}\left[\begin{array}{c}
r_{0, t+1}^{(k)} \\
r_{e, t+1}^{(k)} \\
r_{b, t+1}^{(k)}
\end{array}\right]=\frac{1}{k} M_{r} \operatorname{Var}_{t}\left(\mathrm{z}_{t+1}+\cdots+\mathrm{z}_{t+k}\right) M_{r}^{\prime} .
$$

This approach will be applied to the French data described in the next section.

\section{The French assets return data}

The short term rate is the 3 -month PIBOR rate, obtained from Datastream. The end-ofquarter values from this monthly series are retained to get quarterly observations, and $r_{0 t}$ denotes the real ex post short term rate, i.e. the difference between the log return on the 3 -month PIBOR and the log inflation rate. The inflation series is calculated from the monthly Consumer Price Index series (source: INSEE) as $100 \times\left(c p i_{t}-c p i_{t-12}\right) / c p i_{t-12}$. The log yield on this 3-month PIBOR is also used as the measure of the log short-term nominal interest rates, $r_{0 t}^{n o m}$.

French data for equities prices and returns come from Morgan Stanley Capital International (MSCI) database and are available since December 1969. More precisely, quarterly stock market data are based on the monthly MSCI National Price and Gross Return Indices in local currency. From these data, a quarterly stock total return series and a quarterly dividend series

\footnotetext{
${ }^{4}$ Time variation in $\Sigma_{v}$ could be incorporated in the model, but since the available empirical evidence suggests that the persistence of changes in risk is quite low, this should not affect too much the conclusions regarding long-term asset allocation.
} 
are obtained following the methodology described in Campbell $[1999]^{5}$. Note that we depart from Campbell's approach by not including the tax credits on dividends which are applicable to France. Indeed, MSCI calculates returns from the perspective of US investors, so it excludes from its indices these tax credits which are available only to local investors. Campbell chooses to add back the tax credits quite roughly, by applying the 1992 rate of $33.33 \%$ to all the sample. Nevertheless, this rate hasn't remained fixed over the sample considered here (1970Q1 - 2006Q4). On top of this, the way dividends are taxed has also changed during that period. We couldn't find exact tax rate data for our sample, and guess that on average, the French tax credits system has increased the nominal stock returns by around $40 \%$. Since applying this coefficient to all the observations would be neutral as long as volatility is concerned, we choose to work with data excluding tax credits. The quarterly log real return on the stock index is denoted $r_{e t}$ and defined as the difference between the log return on equities and the log inflation rate. The log excess return on equities is then $x_{e t}=r_{e t}-r_{0 t}$. The log dividend-price ratio, denoted $l d m p_{t}$ is the log dividend less the log price index. Since the quarterly dividend series is calculated from the monthly dividend payments over the past year, this series starts in 1970Q4 only.

Regarding the bond market, the long term government bond yield is used as a proxy variable. The monthly observations come from Datastream, and an end-of-quarter yield has been computed by selecting the end-of-quarter values. Then, the long bond return is constructed from this series using the loglinear approximation technique described in Chapter 14 of Campbell et al. [1997]:

$$
r_{b, n, t+1}^{n o m} \approx D_{n t} y_{n t}-\left(D_{n t}-1\right) y_{n-1, t+1}
$$

where $n$ is the bond maturity, $D_{n t}$ is the bond duration and $Y_{n t}$ is the bond yield from which the $\log$ bond yield obtains as $y_{n t}=\log \left(1+Y_{n t}\right)$. The duration at time $t$ is calculated as:

$$
D_{n t} \approx \frac{1-\left(1+Y_{n t}\right)^{-n}}{1-\left(1+Y_{n t}\right)^{-1}}
$$

where $n$ is set to 10 years. Following Campbell and Viceira [2002], we approximate $y_{n-1, t+1}$ by $y_{n, t+1}$. The log real return on bonds, denoted $r_{b t}$, is the difference between $r_{b t}^{n o m}$ and the $\log$ inflation. The log excess return on bonds is then $x_{b t}=r_{b t}-r_{0 t}$. The log real returns on PIBOR, bonds and equities are plotted in Figure 7, see Appendix.

Finally, the yield spread $\left(s p r_{t}\right)$ is the difference between the 10-year Treasury bond yield from Datastream and the 3-month PIBOR rate, again using end-of-quarter observations.

Table 1 reports sample means and standard deviations in annualized percentage points, except for the dividend-price ratio. To annualize the raw quarterly data, means are multiplied by 400 while standard deviations are multiplied by 200 since the latter increase with the square root of the time interval in serially uncorrelated data. The mean log returns are adjusted by

\footnotetext{
${ }^{5}$ See also Campbell's "Data Appendix for Asset Prices, Consumption and the Business Cycle", March 1998, downloadable from Campbell's homepage.
} 
adding one-half their variance so that they reflect mean gross returns. These statistics are computed for the sample 1970Q4-2006Q4.

Table 1: Sample statistics for real asset log returns

\begin{tabular}{lcc}
\hline \hline & mean & standard deviation \\
& & \\
$r_{0}$ & 2.31 & 1.34 \\
$x_{e}$ & 6.95 & 23.05 \\
$x_{b}$ & 1.38 & 6.55 \\
$r_{0}^{\text {nom }}$ & 7.34 & 1.72 \\
$l d m p$ & -4.95 & 0.56 \\
spr & 1.02 & 1.39 \\
\hline \hline
\end{tabular}

Remind that the stock return here does not include tax credits. When adding back, say, a $40 \%$ tax credit rate, the stock excess return would reach more than $8 \%$ per year. By contrast the excess return of the 10-year Treasury bond is only about $1.4 \%$. Volatility is much higher for stocks than for bonds (23.05\% and $6.55 \%$ resp.).

ADF unit root tests are reported in Table 2. The deterministic component includes at most a constant under the stationary alternative. The lag order of the ADF regression was selected as the smallest one succeeding in eliminating residuals autocorrelation up to order 8 . The unit root null is strongly rejected for $r_{0}, x_{e}, x_{b}$ and $s p r$, whereas it is clearly not rejected

Table 2: ADF Unit Root Tests

\begin{tabular}{lcccccc}
\hline \hline & $r_{0}$ & $x_{e}$ & $x_{b}$ & $r_{0}^{\text {nom }}$ & $l d m p$ & $s p r$ \\
& & & & & & \\
ADF stat & $-2.84(1)$ & $-11.54(0)$ & $-9.29(0)$ & $-2.04(1)$ & $-1.50(0)$ & $-4.57(1)$ \\
p-value & 0.055 & 0.000 & 0.000 & 0.268 & 0.530 & 0.000 \\
\hline \hline
\end{tabular}

Number of autoregressive lags into parenthesis.

for the dividend-price ratio and for the nominal short term rate.

\section{The VAR model estimates}

In the sequel, we will consider the same model as Campbell and Viceira [2002], i.e. $\mathrm{z}_{t}=$ $\left(r_{0, t}, x_{e, t}, x_{b, t}, r_{0, t}^{n o m}, l d m p_{t}, s p r_{t}\right)$ in equation (1). The first four variables are multiplied by 100. The lag order of is set to one, according to both Akaike, Schwartz and Hannan-Quinn information criteria. Moreover, the null of no residuals autocorrelation up to order 8 is not rejected at the $6 \%$ level according to Box-Pierce statistics. 
Due to the stock market data, our sample is 1970Q4-2006Q4, i.e. 145 observations. The VAR is thus estimated from 1971Q1 to 2006Q4. The results are reported in Table 3. The first column reports the real 3 -month rate equation. The lagged 3 -month rate and the lagged spread coefficients are significantly different from zero and hence help predicting the real 3month return. The second column refers to the real stock log return equation. This variable is known to be hardly predictable, which is here confirmed by the $R^{2}$ value of $10 \%$. Nevertheless, the lagged bond log return and the lagged dividend-price ratio coefficients are significantly different from zero. The third column shows that both lagged 3-month return, bond return and yield spread help predicting the log bond return. The $R^{2}$ of this equation is $12 \%$. The last three columns reveal that the return forecasting variables are highly persistent, especially the nominal short rate and the dividend-price ratio. In order to check for the VAR model stability, we have computed the roots of its characteristic polynomial: it turns out that the modulus of the largest root is lesser than one, with a value of 0.97. Hence the VAR apparently satisfies the stability condition.

Table 4 reports standard deviations of estimated residuals on the diagonal and their correlations off-diagonal.

The magnitude of real returns residuals standard deviations obtained here are somehow similar to those obtained on quarterly data by Campbell et al. [2003] and Campbell and Viceira [2005]. ${ }^{6}$ Indeed, these authors find $0.57,8.06$ and 2.69 for $r_{0}, x_{e}$ and $x_{b}$ respectively, to compare with our values of $0.23,11.23$ and 3.14 . The residuals cross-correlations are also quite similar to those found by these authors, except for the log real short-term rate equation: contrary to their results, we find that unexpected real short-term returns are negatively correlated with log bond excess returns and yield spread innovations, and positively correlated with nominal short-term rate innovations. Unexpected log excess stock returns are highly negatively correlated with shocks to the log dividend-price ratio, and mildly positively correlated with unexpected log excess bond returns and yield spread innovations. Finally, unexpected log excess bond returns are negatively correlated with shocks to the nominal short-term rate and to a lesser extend with shocks to real short-term returns. They are weakly positively correlated to yield spread innovations.

The signs of these innovations cross-correlations may explain some results. As shown by Stambaugh [1999], the small-sample bias in such regressions has the opposite sign to the sign of the correlation between innovations in returns and innovations in predictive variables. Hence, one may suspect that for the 3-month return equation, where the spread innovations are negatively correlated with returns innovations, there is a positive small-sample bias which may in turn explain some apparent predictability. On the contrary, the positive correlation between bond return and yield spread innovations suggests that the predictability of bond returns is not overstated in our sample. Regarding the log excess stock returns equation, the

\footnotetext{
${ }^{6}$ Campbell et al. [2003] use quarterly US data from 1952Q2 to 1999Q4 while Campbell and Viceira [2005] extend the sample until 2002Q4.
} 
Table 3: VAR estimation results

\begin{tabular}{|c|c|c|c|c|c|c|}
\hline & $r_{0, t}$ & $x_{e, t}$ & $x_{b, t}$ & $r_{0, t}^{\text {nom }}$ & $l d m p_{t}$ & $s p r_{t}$ \\
\hline$r_{0, t-1}$ & $\begin{array}{c}\mathbf{0 . 9 3 1} \\
(0.058) \\
{[15.91]}\end{array}$ & $\begin{array}{c}\mathbf{6 . 4 4 4} \\
(2.833) \\
{[2.27]}\end{array}$ & $\begin{array}{c}\mathbf{1 . 7 4 7} \\
(0.793) \\
{[2.20]}\end{array}$ & $\begin{array}{c}-0.040 \\
(0.058) \\
{[-0.69]}\end{array}$ & $\begin{array}{c}\mathbf{- 0 . 1 0 9} \\
(0.033) \\
{[-3.33]}\end{array}$ & $\begin{array}{r}-0.156 \\
(0.211) \\
{[-0.74]}\end{array}$ \\
\hline$x_{e, t-1}$ & $\begin{array}{c}0.001 \\
(0.002) \\
{[0.42]}\end{array}$ & $\begin{array}{c}-0.016 \\
(0.091) \\
{[-0.17]}\end{array}$ & $\begin{array}{c}-0.024 \\
(0.026) \\
{[-0.94]}\end{array}$ & $\begin{array}{c}0.001 \\
(0.002) \\
{[0.59]}\end{array}$ & $\begin{array}{c}-0.000 \\
(0.001) \\
{[-0.38]}\end{array}$ & $\begin{array}{r}-0.002 \\
(0.007) \\
{[-0.33]}\end{array}$ \\
\hline$x_{b, t-1}$ & $\begin{array}{c}-0.005 \\
(0.006) \\
{[-0.79]}\end{array}$ & $\begin{array}{c}\mathbf{0 . 6 2 0} \\
(0.307) \\
{[2.02]}\end{array}$ & $\begin{array}{c}\mathbf{0 . 2 4 3} \\
(0.086) \\
{[2.82]}\end{array}$ & $\begin{array}{c}\mathbf{- 0 . 0 2 1} \\
(0.006) \\
{[-3.29]}\end{array}$ & $\begin{array}{c}-0.006 \\
(0.003) \\
{[-1.74]}\end{array}$ & $\begin{array}{r}\mathbf{0 . 0 5 4} \\
(0.023) \\
{[2.35]}\end{array}$ \\
\hline$r_{0, t-1}^{n o m}$ & $\begin{array}{c}0.078 \\
(0.047) \\
{[1.68]}\end{array}$ & $\begin{array}{c}-4.217 \\
(2.261) \\
{[-1.86]}\end{array}$ & $\begin{array}{c}-0.238 \\
(0.633) \\
{[-0.37]}\end{array}$ & $\begin{array}{c}\mathbf{1 . 0 1 4} \\
(0.046) \\
{[21.89]}\end{array}$ & $\begin{array}{c}\mathbf{0 . 0 5 3} \\
(0.026) \\
{[2.04]}\end{array}$ & $\begin{array}{r}-0.027 \\
(0.168) \\
{[-0.16]}\end{array}$ \\
\hline$l d m p_{t-1}$ & $\begin{array}{c}-0.146 \\
(0.083) \\
{[-1.76]}\end{array}$ & $\begin{array}{c}\mathbf{8 . 6 1 7} \\
(3.997) \\
{[2.15]}\end{array}$ & $\begin{array}{c}0.933 \\
(1.118) \\
{[0.83]}\end{array}$ & $\begin{array}{c}-0.074 \\
(0.082) \\
{[-0.91]}\end{array}$ & $\begin{array}{c}\mathbf{0 . 8 5 0} \\
(0.046) \\
{[18.39]}\end{array}$ & $\begin{array}{c}0.153 \\
(0.297) \\
{[0.52]}\end{array}$ \\
\hline$s p r_{t-1}$ & $\begin{array}{c}\mathbf{0 . 0 7 0} \\
(0.018) \\
{[3.78]}\end{array}$ & $\begin{array}{c}1.537 \\
(0.893) \\
{[1.72]}\end{array}$ & $\begin{array}{c}\mathbf{0 . 6 1 8} \\
(0.250) \\
{[2.47]}\end{array}$ & $\begin{array}{c}\mathbf{0 . 0 4 3} \\
(0.018) \\
{[2.35]}\end{array}$ & $\begin{array}{c}\mathbf{- 0 . 0 2 1} \\
(0.010) \\
{[-2.09]}\end{array}$ & $\begin{array}{r}\mathbf{0 . 7 2 9} \\
(0.066) \\
{[10.98]}\end{array}$ \\
\hline$c$ & $\begin{array}{c}-0.899 \\
(0.460) \\
{[-1.95]}\end{array}$ & $\begin{array}{c}\mathbf{4 6 . 0 2 4} \\
(22.278) \\
{[2.07]}\end{array}$ & $\begin{array}{c}3.697 \\
(6.235) \\
{[0.59]}\end{array}$ & $\begin{array}{c}-0.414 \\
(0.456) \\
{[-0.91]}\end{array}$ & $\begin{array}{c}\mathbf{- 0 . 7 5 7} \\
(0.258) \\
{[-2.94]}\end{array}$ & $\begin{array}{r}1.155 \\
(1.656) \\
{[0.70]}\end{array}$ \\
\hline R-squared & 0.88 & 0.10 & 0.12 & 0.93 & 0.95 & 0.66 \\
\hline
\end{tabular}


Table 4: Standard deviations and correlations of residuals

\begin{tabular}{lcccccc}
\hline \hline & $r_{0}$ & $x_{e}$ & $x_{b}$ & $r_{0}^{\text {nom }}$ & ldmp $p_{t}$ & spr $_{t}$ \\
& & & & & & \\
$r_{0}$ & 0.232 & -0.267 & -0.377 & 0.806 & 0.145 & -0.742 \\
$x_{e}$ & - & 11.230 & 0.243 & -0.301 & -0.804 & 0.198 \\
$x_{b}$ & - & - & 3.142 & -0.571 & -0.231 & 0.071 \\
$r_{0}^{\text {nom }}$ & - & - & - & 0.230 & 0.250 & -0.857 \\
$l d m p$ & - & - & - & - & 0.130 & -0.150 \\
spr & - & - & - & - & - & 0.835 \\
\hline \hline
\end{tabular}

predictability due to the log dividend-price ratio may be overstated due to the quite strong negative correlation between stock returns and dividend-price ratio innovations.

\section{Comparing French assets risk across investment horizons}

The conditional $k$-period variance-covariance matrix of real returns is obtained from the $\operatorname{VAR}(1)$ estimates according to equation (4). The conditional standard deviation of the cumulative returns over investment horizon is divided by the square root of the horizon, so as to get annualized values. The annualized percent standard deviations of real returns for investment horizons up to 100 quarters, i.e. 25 years, are plotted in Figure 1.

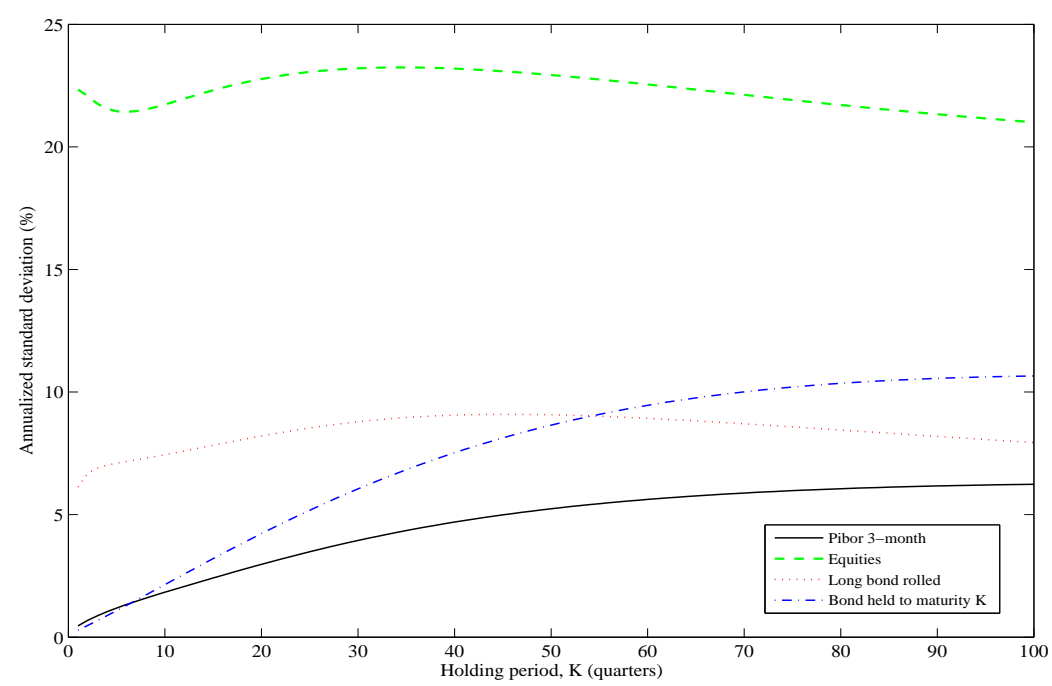

Figure 1: Annualized percent standard deviations of real returns 
If returns were i.i.d., Siegel's measure of risk, i.e., the standard deviation of annualized returns, would be independent of the investment horizons. Hence, finding evidence that risk does not scale with horizon in this way would tend to confirm the predictability of returns. This is precisely the case here since the standard deviations plotted in Figure 1 depend on the investment horizon. Stock returns appear slightly less volatile at longer horizons than at shorter ones. In this sense, French stocks are mean-reverting. The same result is obtained for annual and quarterly US data by Campbell and Viceira [2002], Campbell et al. [2003] and Campbell and Viceira [2005]. However, French stock returns volatility decreases lesser than its US analogue: here, it drops from $22.3 \%$ to $21 \%$ after 25 years whereas the US stock returns volatility is only around $8 \%$ at this long horizon, according to Campbell and Viceira [2005] results.

This finding is a direct consequence of our VAR analysis. The mean-reversion of stocks return can be inferred from different channels. For example, we see in Table 3 that the autoregressive coefficient of the excess return of stocks is negative. But we also see that the dividend-price ratio is a good predictor of the future stocks return. Moreover, shocks to the excess return and to the dividend-price ratio are strongly negatively correlated, as seen in Table 4. It implies that a positive shock on the excess return of stocks yields a negative shock on the dividend-price ratio, which in turn yields an downwards revision of the expectation of future stocks returns.

Regarding bonds, two kinds of investment strategies are considered from the estimated model. The long bond rolled strategy is the one implicitly assumed in long-term bond returns time series: the maturity of the bond is held constant at, say, 10 years, buying a 10-year bond each period and selling it next period so as to buy a new 10-year bond. The second strategy consists in buying a bond and holding it until maturity. In this case, the standard deviation of the real return is given by the standard deviation of cumulative inflation from time $t$ to time $t+K$, since this nominal bond held to maturity is riskless in nominal terms.

Contrary to Campbell and Viceira [2005], we find that the long bond rolled strategy is slightly mean-averting. Note however that using annual data, Campbell and Viceira [2002] find a mean-averting behavior for this return. Starting from about $6 \%$ at short horizons, the long bond rolled real return volatility reaches $8 \%$ at the 25 -year horizon. Even though the long bond rolled return volatility is always lesser than the one for stocks, the gap reduces from $16 \%$ at the one-quarter horizon to $13 \%$ at the 25 -year horizon, see Figure 2. The real returns on both PIBOR and the variable-maturity bond are even more mean-averting. The volatility of the later becomes greater than the one of the PIBOR after five quarters and than the one of the long bond rolled after around thirteen years. Campbell and Viceira [2005] reach the similar conclusion: the return on the variable-maturity bond becomes riskier than the long bond rolled from the 8-year horizon on. While their study also finds that the return on the variable-maturity bond becomes riskier than the stock return for horizons greater than thirtytwo years, it turns out from our data that the variable-maturity bond risk never exceeds the 
stock risk, whatever the investment horizon considered. Finally, their study reveals that the return on short term T-bills becomes riskier than the return on long bond rolled after around forty-five years; this phenomenon does not occur in our data.

Overall, the stock real return is always riskier than the other assets considered here. For horizons longer than thirteen years, the return volatility of variable-maturity bond exceeds the ones of both the constant-maturity bond and the 3-month PIBOR. From the one-year investment horizon on, the 3-month PIBOR becomes the less risky asset.

Regarding the excess risk of stock returns, which is crucial in terms of portfolio allocation, Figure 2 shows that it decreases as horizon grows with respect to all other assets classes considered here. Starting from $22 \%$ with respect to the 3 -month rate and the variable maturity bond, this excess risk in stocks falls to $14.7 \%$ and $10.3 \%$ respectively after 25 years. The excess risk of stocks compared to the long bond rolled strategy falls from $16.2 \%$ to $13 \%$ at the 25 -year horizon. Omitting this excess risk mean-reversion would clearly lead to understate the share of stocks in the portfolio choice of long-horizon investors.

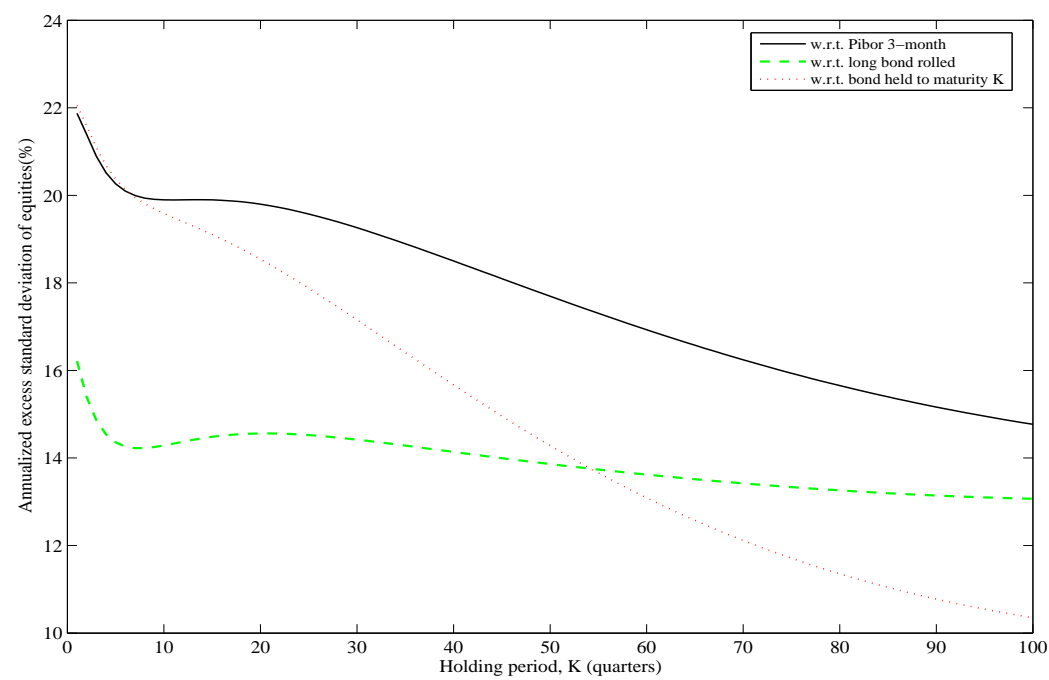

Figure 2: Excess risk of stocks compared to other assets

From the conditional variance-covariance matrix given in equation (5), it is straightforward to compute the correlations of the real returns at all horizons. Figure 3 shows that the correlations of stocks return and both fixed and variable-maturity long bonds return are positive at all horizons. At the one-quarter horizon, the correlation between stock and variable-maturity bond (resp. fixed-maturity bond) returns is around 3\% (resp. 11\%). It then peaks at $36 \%$ (resp. 35\%) at the 10-year horizon. At the 25-year horizon, the stock-variable-maturity bond correlation is still $34 \%$, whereas the stock-fixed-maturity bond correlation decreases to $29 \%$. 
More striking hump-shaped patterns are also present in Campbell and Viceira [2005]'s study. The main discrepancy in our findings is that the correlation between stock and bond held to maturity returns remains positive at all horizons, even for the 50-year horizon, while Campbell and Viceira [2005] find that this correlation becomes negative after 45 years. Accordingly, they claim that stocks are able to hedge inflation risk in the very long term. This feature is not shared by French data. However, as stressed by these authors, the very long horizons predictions of the model must be cautiously interpreted because of the size of the sample.

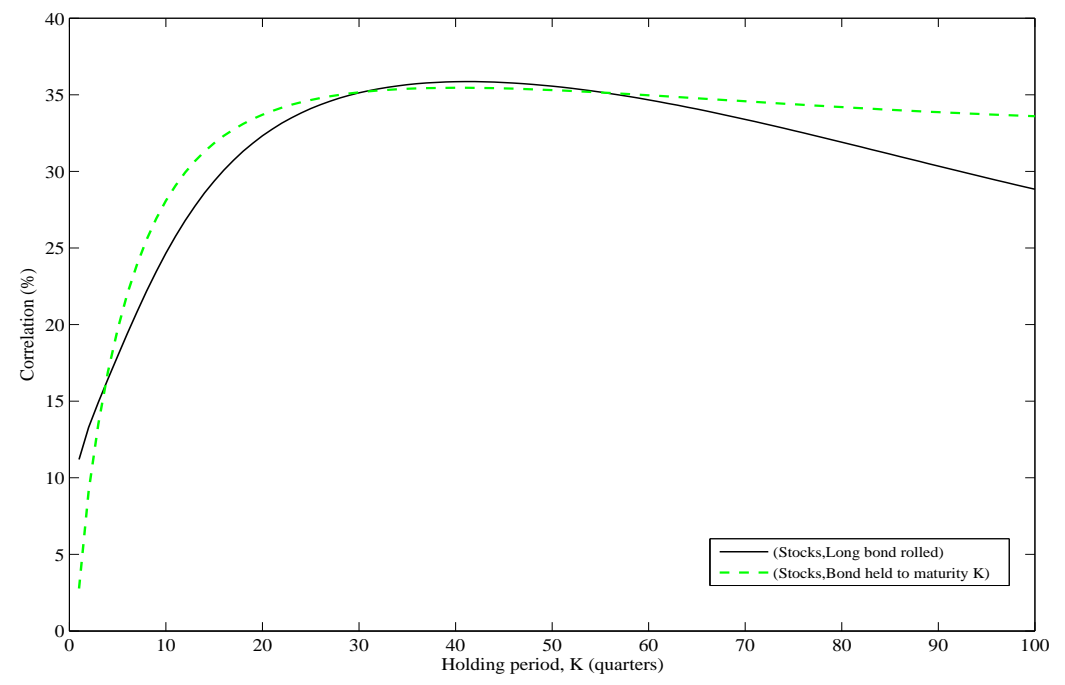

Figure 3: Correlations of real returns implied by VAR(1) estimates

\section{$5 \quad$ Robustness analysis}

The conclusions drawn above rely entirely on the VAR(1) model estimates reported in Tables 3 and 4 . We propose to check their robustness along three dimensions. Firstly, we will extend the methodology proposed in Campbell and Viceira [2002] by taking the standard errors of $\Phi_{0}$, $\Phi_{1}$ and $\Sigma_{v}$ OLS estimates into account. Secondly, the stability of the coefficients estimates will be checked using the structural break analysis developed by Bai, Lumsdaine and Stock [1998]. Indeed, the Sup test developed by these authors allows to test the null of VAR parameters stability against the alternative of a structural change at unknown date. Thirdly, motivated by the unit root tests reported in Section 2, different information sets will be considered. 


\subsection{Bootstrapped confidence intervals for the curves of annualized standard deviation}

Rather surprisingly, the confidence intervals of the annualized standard deviation curves are neither reported nor commented in existing empirical work. Yet, since the OLS estimates of $\Phi_{0}, \Phi_{1}$ and $\Sigma_{v}$ have of course a non-zero variance-covariance matrix, i.e. are measured with uncertainty, nothing ensures a priori that the difference between the curves in e.g. figure 1 is statistically significant.

In order to check this, the parametric residual bootstrap method described in e.g. Hansen and Seo [2002] is used. From the model given by equation (1), assuming that $\mathrm{v}_{t}$ is i.i.d. from an unknown distribution, and for fixed initial conditions on $z_{t}$, the bootstrap distribution may be calculated by simulation. Random draws are made from the estimated residuals vector $\widehat{v}_{t}$ and then the simulated vector series $z_{t}^{s}$ are computed by recursion given model (1). 10,000 vector series $z_{t}^{s}$ are created, with the same length as the sample size. The initial condition is set to the actual value. For each simulated $z_{t}^{s}, \widehat{\Phi}_{0}^{s}, \widehat{\Phi}_{1}^{s}$ and $\widehat{\Phi}_{v}^{s}$ are obtained from the OLS estimation of equation (1). From these matrices, the corresponding annualized standard deviations of simulated real returns are computed. For each kind of assets, figure 4 below reports the $5 \%$ and $95 \%$ quantiles associated to annualized standard deviations obtained from the 100,000 drawings. This figure reveals that once their $95 \%$ confidence intervals are taken

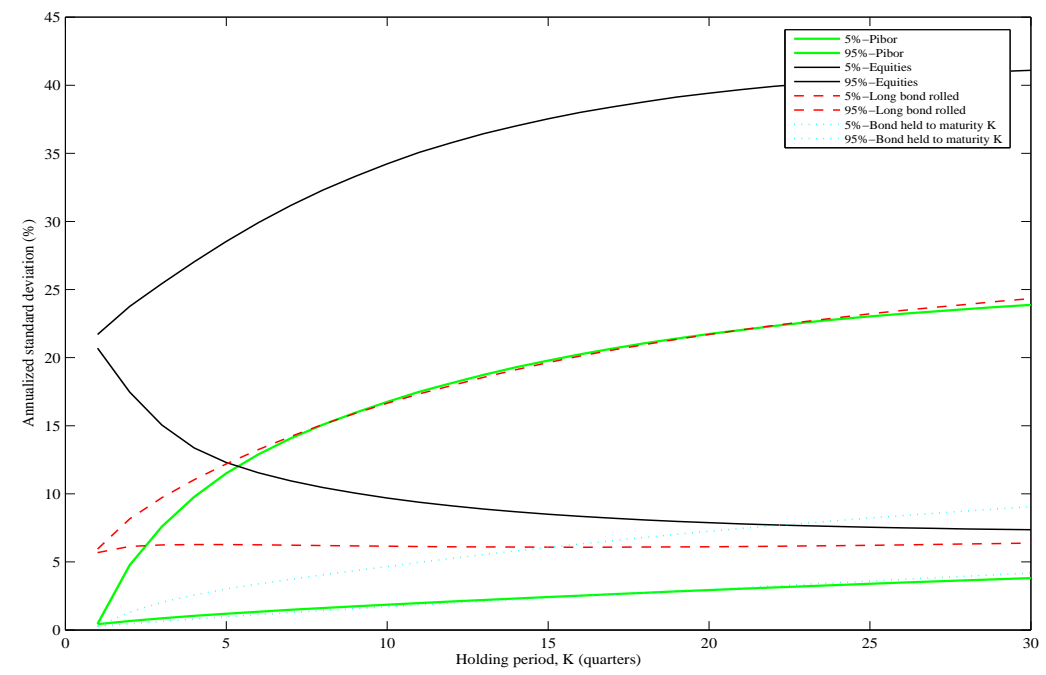

Figure 4: 95\% Confidence Intervals for risks across horizons

into account, the risks corresponding to the short rate, the long bond rolled and the bond held to maturity are not significantly different from each other after the one-year horizon. Indeed, 
their confidence intervals intersect very quickly. Moreover, the short term rate and long bond rolled risk confidence intervals cross the one of equities at the 5-quarter horizon. From that horizon on, equities risk is not significantly higher than these two ones. Only the bond held to maturity risk remains significantly lower than the one of equities until the 6-year horizon.

\section{$5.2 \quad$ Stability analysis}

The liberalization of the French financial markets in the mid-eighties may have affected the returns dynamics over, say, the second half of our sample. If it were actually the case, then our conclusions would be biased since the VAR model given in equation (1) does not allow for a structural change. In order to allow for a general structural change at time $\tau=T \lambda$, with $\lambda \in(0,1)$, the VAR model can be generalized as follows:

$$
\mathrm{z}_{t}=\Phi_{0}+\Phi_{1} \mathrm{z}_{t-1}+D(t>\tau)\left(\Gamma_{0}+\Gamma_{1} \mathrm{z}_{t-1}\right)+\mathrm{u}_{t},
$$

where $\Gamma_{0}$ and $\Gamma_{1}$ are respectively $m \times 1$ and $m \times m$ matrices, $\mathrm{u}_{t}$ is the $m \times 1$ vector of innovations assumed to be i.i.d. with $E\left(\mathbf{u u}_{t}^{\prime}\right)=\Sigma_{u} . D(t>\tau)$ is a dummy variable such that $D(t>\tau)=0$ for $t \leq \tau$ and $D(t>\tau)=1$ for $t>\tau$. Under the null hypothesis that no break occurs, model (6) reduces to the VAR given in equation (1):

$$
\mathrm{z}_{t}=\Phi_{0}+\Phi_{1} \mathrm{z}_{t-1}+\mathrm{v}_{t}
$$

with $E\left(\mathrm{v}_{t} \mathrm{v}_{t}^{\prime}\right)=\Sigma_{v}$. Hence, the null hypothesis of no structural break at time $\tau$ corresponds to:

$$
H_{0}: \Gamma_{0}=0_{m \times 1} \text { and } \Gamma_{1}=0_{m \times m} .
$$

If the break point $\tau$ were known, then standard likelihood ratio (LR), Lagrange Multiplier (LM) or Wald (W) test statistics could be used to test $H_{0}$. If $\tau$ is unknown, the difficulty is that there is no estimate of $\tau$ under the null hypothesis: $\tau$ is a nuisance parameter under the null. The parameters $\mu_{1}$ and $B$ are also unidentified nuisance parameters under $H_{0}$. With $\tau$ unknown, we will follow the common practice initiated by Davies [1987] which consists in using sup tests of the type:

$$
\operatorname{Sup} L R(\tau)=\sup _{\tau \in\left[\tau_{\text {inf }}, \tau_{\text {sup }}\right]} L R_{T}(\tau)
$$

where $\tau_{\text {inf }}$ corresponds to the initial fraction of the full sample $T$ which is trimmed, in practice often set to $0.15 T$ as suggested by Andrews [1993] and $\tau_{\text {sup }}=\left(1-\tau_{\text {inf }}\right) T$. In our case, since the sample length is 145 and the number of parameters is 42 , the trimming parameter is chosen so as to leave 42 observations before the first break date $\tau_{\text {inf }}$ and after the last break date $\tau_{\text {sup }}$. Moreover,

$$
L R_{T}(\tau)=\left(T-n_{c}\right)\left(\log \operatorname{det}\left(\Sigma_{v}\right)-\log \operatorname{det}(\Sigma(\tau))\right)
$$


where $n_{c}$ denotes the number of constrained coefficients involved by assumption (7). Note that the LR statistics depends on $\tau$ through the estimate of the variance-covariance matrix of residuals under the alternative (6). Equivalently, one could define SupLM and SupW statistics. As can be shown from Andrews [1993] and Bai et al. [1998], the asymptotic null distribution of $\operatorname{SupLR}(\lambda)$ is free of nuisance parameter. Hence, the critical values for the test statistics can be tabulated. However, as the empirical use of it will involve a finite number of observations, we will rather use a residual bootstrap method calculated by simulation. For given initial conditions, random draws are made from the residual vectors under the null. From these bootstrap residuals, one can create a simulated sample of series using model (1), and for each sample, calculate the corresponding $S u p L R$ statistic. The bootstrap $p$-value then obtains as the percentage of simulated statistics which exceed the actual statistics. ${ }^{7}$

For a set of break dates ranging from 1981Q1 to 1996Q4, the SupLR statistic is 72.93, and its bootstrapped p-value - computed from 5000 replications - is $48.37 \%$. Consequently, the null of parameters stability cannot be rejected for our $\operatorname{VAR}(1)$ model.

\subsection{Change in the information set}

As stressed earlier, the estimation results given in Tables 3 and 4 must be cautiously considered since the univariate unit root tests do not reject the null hypothesis for the log nominal shortterm rate and for the log dividend-price ratio. Even though the largest root of the VAR(1) characteristic polynomial is lesser than one, it is still very close to unity with a value of 0.97 . Johansen's cointegration rank test further confirms that this value may not be significantly different from unity. ${ }^{8}$

Therefore, we propose to check the robustness of our conclusions by substituting the first differences to the levels of these variables. Nevertheless, the first differences of the nominal short rate and of the dividend-price ratio do not help predicting the real returns ${ }^{9}$. Hence, we reintroduce the $\log$ of the dividend to price ratio in levels, since it seems to be an important predictor of the stocks returns. The results obtained from the 5-dimensional vector $\mathrm{z}_{t}^{*}=$ $\left(r_{0, t}, x_{e, t}, x_{b, t}, l d m p_{t}, s p r_{t}\right)$ are quite similar to the ones from the 6-variable system. Again, the information criteria point to a lag length of one and the Box-Pierce statistics does not reject the null of no residuals autocorrelation up to order 8. This VAR model in $z_{t}^{*}$ is thus estimated using the same sample as the VAR in $z_{t}$, namely 1971Q1-2006Q4. The largest root of the characteristic polynomial is now 0.94 in absolute value and Johansen's trace test allows to conclude that the cointegration rank is four at the $6 \%$ level, hence suggesting the stability of this multidimensional system. The estimated equations of the five remaining variables are basically unchanged compared to the 6 -variable system. Since the nominal short rate has been

\footnotetext{
${ }^{7}$ A detailed description of the method can be found in e.g. Hansen [1996] or Hansen and Seo [2002].

${ }^{8}$ The trace test concludes to four cointegration relations at most, at the $10 \%$ level, hence indicating two common trends.

${ }^{9}$ Results not reported but available upon request.
} 
excluded from this model, the inflation rate dynamics cannot be recovered from the system. Consequently, it is now impossible to compute the conditional moments of the variable-maturity bond strategy. The annualized standard deviations of the real returns on the three remaining assets are reported in Figure 5. The pattern of the stock real return volatility is very similar to one obtained in the previous section: the standard deviation reaches $22.5 \%$ at the one-quarter horizon, peaks at $23 \%$ at the six-year horizon and then slowly decreases until it reaches $21 \%$ at the 25-year horizon. Compared to the 6 -variable model, the pattern of the 3 -month PIBOR

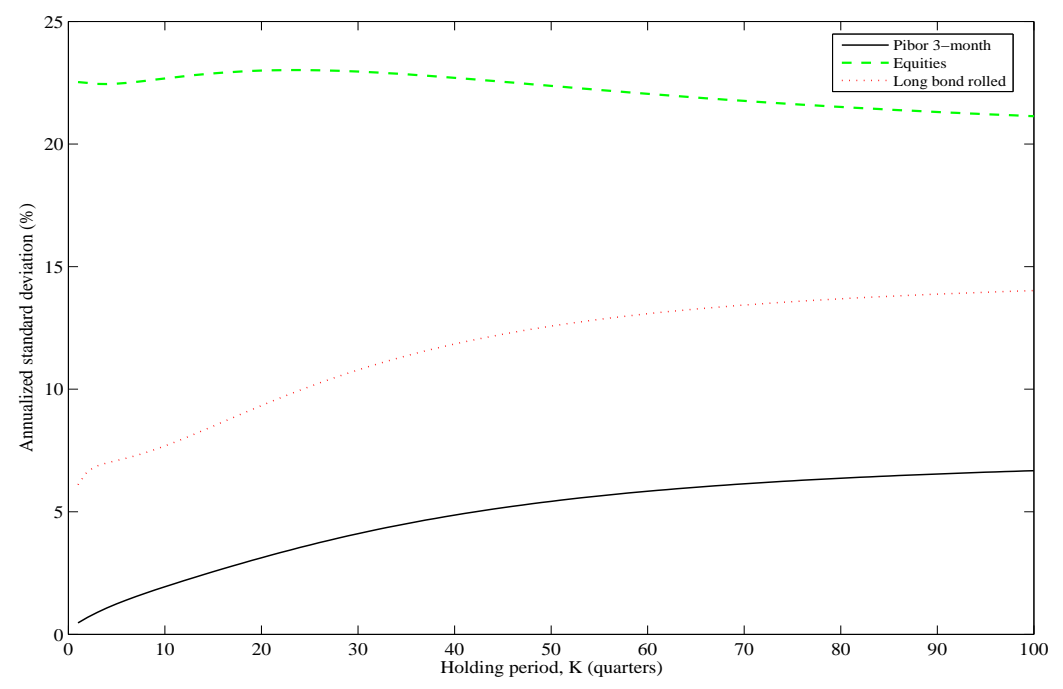

Figure 5: Annualized percent standard deviations of real returns $\left(\mathbf{z}_{t}^{*}\right)$

real returns volatilities remain largely unchanged. By contrast, the long bond rolled strategy appears even more mean-averting, growing from $6 \%$ to $14 \%$ between the one-quarter and the 25 -year horizons. So, in this 5 -variable model,the equities return is always riskier than the long bond return which in turn is always riskier than the 3-month PIBOR rate. Moreover, as can be seen from Figure 6, the volatility differentials strongly decrease with the investment horizon, hence leaving the conclusions unchanged compared with the previous model.

\section{Concluding remarks}

The aim of this paper was to assess French assets returns predictability within a VAR setup. Using quarterly data from 1970Q4 to 2006Q4, it turns out that bonds, equities and bills returns are actually predictable, at least to some extend. This feature has important consequences in terms of multiperiod portfolio choice. It implies that the investment horizon does indeed matter in the asset allocation. Following the approach developed by Campbell and Viceira [2002], the 


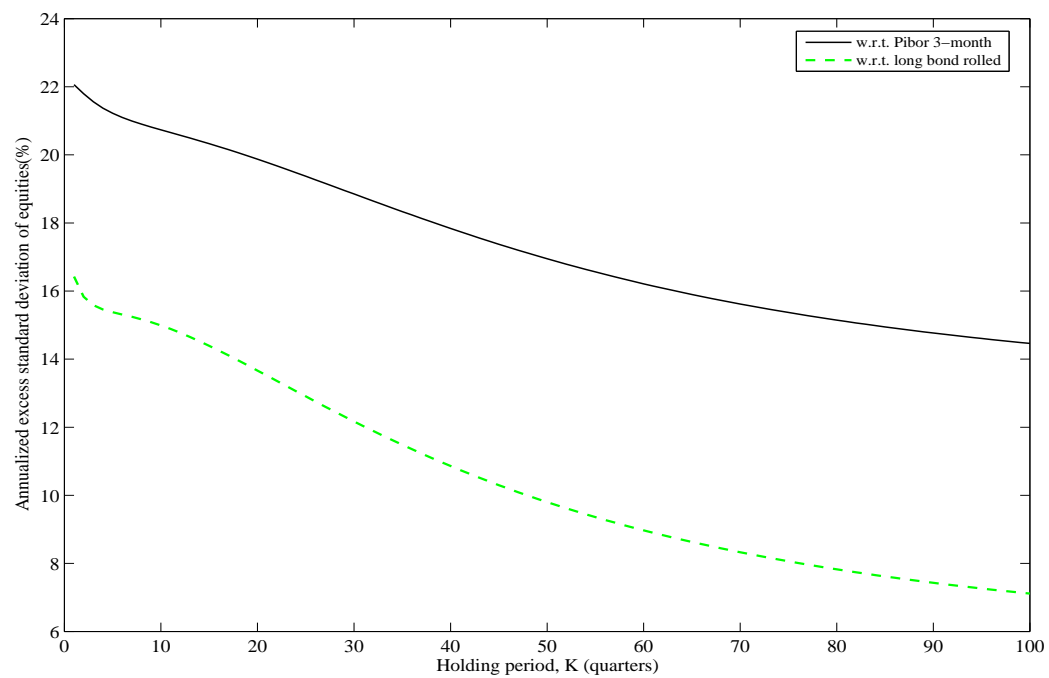

Figure 6: Correlations of real returns $\left(\mathrm{z}_{t}^{*}\right)$

VAR parameters estimates are used to compute real returns conditional moments of order two. From a six-variable VAR model similar to the one estimated by these authors, we actually find an horizon effect for French data.

In particular, French stock market return is slightly mean-reverting while bonds and bills returns are mean-averting. Consequently, the gap between stock risk and other assets risk reduces as the horizon gets longer. Whereas this gap is around $22 \%$ at the one-quarter horizon for stocks compared to the 3-month rate and the bond held to maturity, it falls to $14.7 \%$ and $10.3 \%$ respectively at the 25 -year horizon. The gap between the stock and constant maturity bond risks decreases from $16.2 \%$ to $13 \%$.

Compared to Campbell and Viceira [2002] and Campbell and Viceira [2005] results, French stocks returns appear less strongly mean-reverting than their US analogues. It is also worth noting that the 25-year horizon volatility of the four French assets considered here ranks from $6 \%$ to $21 \%$. By contrast, their US analogues lie between $3 \%$ and $8 \%$. Regarding the conditional correlation between assets across investment horizons, French data reveal the same kind of patterns as the ones found by Campbell and Viceira [2005], namely an increasing correlation at the short and medium horizons.

Finally, our main conclusions suggest that long-horizon investors may well overstate the share of bonds in their portfolio choice when neglecting the horizon effect on risk of asset returns predictability. 


\section{References}

Andrews, D.W.K., Tests for Parameter Instability and Structural Change with Unknown Change Point, Econometrica, 1993, 61, 821-856.

Bai, J., R.L. Lumsdaine, and J.H. Stock, Testing For and Dating Common Breaks in Multivariate Time Series, Review of Economic Studies, 1998, 65, 395-432.

Barberis, N., Investing for the long run when returns are predictable, Journal of Finance, 2000, 55, 225-264.

Campbell, J., A variance decomposition for stock returns, Economic Journal, 1991, 101, 157-179.

_ _ Understanding risk and return, Journal of Political Economy, 1996, 104, 298-345.

, Asset Prices, Consumption, and the Business Cycle, in J. Taylor and M. Woodford, editors, Handbook of Macroeconomics, vol.1, North-Holland: Amsterdam, 1999, pp. 12311303.

_, A. Lo, and A. MacKinlay, The Econometrics of Financial Markets, Priceton: Priceton University Press, 1997.

_ and L. Viceira, Consumption and portfolio decisions when expected returns are time varying, Quarterly Journal of Economics, 1999, 114, 433-495.

_ _ and _ Strategic Asset Allocation, Oxford University Press, 2002.

_ Economics, Harvard University, Cambridge MA 2004.

— and _ - The Term Structure of the Risk-Return Tradeoff, Working Paper 11119, NBER, Cambridge MA 2005.

_, Y. Chan, and L. Viceira, A Multivariate Model of Strategic Asset Allocation, Journal of Financial Economics, 2003, 67, 41-80.

Cochrane, J., Asset Pricing, Priceton: Priceton University Press, 2001.

Davies, R. B., Hypothesis Testing When a Nuisance Parameter is Present Only Under the Alternative, Biometrika, 1987, 74, 33-43.

Dimson, E., P. Marsh, and M. Staunton, Triumph of the Optimists: 101 Years of Global Investment Returns, Princeton: Princeton University Press, 2002.

Fama, E. and K. French, Dividend yields and expected stock returns, Journal of Financial Economics, 1988, 22, 3-27. 
Gollier, C. and R. Zeckhauser, Time horizon and portfolio risk, Journal of Risk and Uncertainty, 2002, 24, 195-212.

Hansen, B. and B. Seo, Testing for Two-Regime Threshold Cointegration in Vector ErrorCorrection Models, Journal of Econometrics, 2002, 110, 293-318.

Hansen, B.E., Inference when a Nuisance Parameter Is Not Identified Under the Null Hypothesis, Econometrica, 1996, 64 (2), 413-430.

Merton, R., Lifetime portfolio selection under uncertainty: The continous time case, Review of Economics and Statistics, 1969, 51, 247-257.

, An intertemporal capital asset pricing model, Econometrica, 1973, 41, 867-887.

Mossin, J., Optimal multiperiod portfolio policies, Journal of Business, April 1968, pp. 215229.

Poterba, J. and L.H. Summers, Mean reversion in stock returns: Evidence and implications, Journal of Financial Economics, 1988, 22, 27-60.

Samuelson, P., Lifetime portfolio selection by dynamic stochastic programming, Review of Economics and Statistics, 1969, 51, 239-246.

Stambaugh, R., Predictive Regressions, Journal of Financial Economics, 1999, 54, 375-421. 


\section{Appendix}
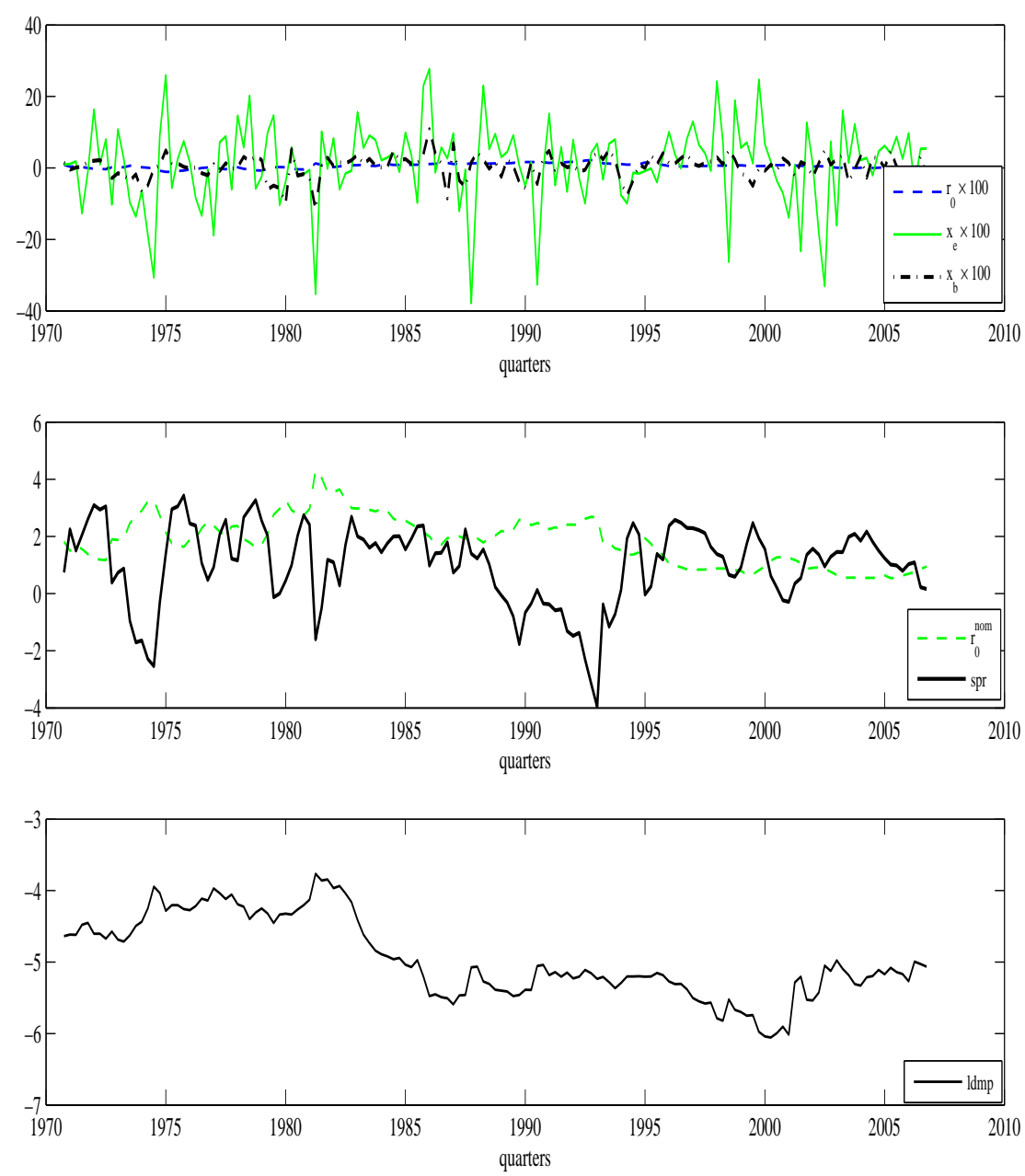

Figure 7: French data (1970Q4-2006Q4) 